\title{
The Role of Parental Warmth and Hostility on Adolescents' Prosocial Behavior Toward Multiple Targets
}

\author{
Laura M. Padilla-Walker \\ Brigham Young University, laura_walker@byu.edu
}

Matthew G. Nielson

Randal D. Day

Follow this and additional works at: https://scholarsarchive.byu.edu/facpub

Part of the Social and Behavioral Sciences Commons

\section{Original Publication Citation}

Padilla-Walker, L. M., *Nielson, M. G., \& Day, R. A. (2016). The role of parental warmth and hostility on adolescents' prosocial behavior toward multiple targets. Journal of Family Psychology, 30, 331-340.

\section{BYU ScholarsArchive Citation}

Padilla-Walker, Laura M.; Nielson, Matthew G.; and Day, Randal D., "The Role of Parental Warmth and Hostility on Adolescents' Prosocial Behavior Toward Multiple Targets" (2015). Faculty Publications. 5508. https://scholarsarchive.byu.edu/facpub/5508 


\title{
The Role of Parental Warmth and Hostility on Adolescents' Prosocial Behavior Toward Multiple Targets
}

\author{
Laura M. Padilla-Walker, Matthew G. Nielson, and Randal D. Day \\ Brigham Young University
}

\begin{abstract}
The current study examined the influence that parental warmth/support and verbal hostility had on adolescents' prosocial behavior toward multiple targets (stranger, friend, family) using multiple reporters (self, parent, observations). Data were taken from Times 2 and 3 of a longitudinal project and included 500 adolescents and their parents $(M$ age of child at Time $2=12.34$ ). Structural equation models suggested that mother warmth was associated with prosocial behavior toward family, while father warmth was associated with prosocial behavior toward friends. Findings also suggested that adolescents' prosocial behavior was more consistently influenced by father hostility than it was by father warmth. Finally, observational reports of father hostility were associated with adolescent prosocial behavior more consistently than self- or child-reported parenting. The discussion focuses on the importance of considering target of prosocial behavior, the differences between mothers and fathers, and the role of self-reports compared to observations.
\end{abstract}

Keywords: prosocial behavior, parenting, adolescence, warmth, hostility

Prosocial behavior, or voluntary behavior meant to benefit others, has gained increased attention in recent years as a foundation of social competence and the development of morality during childhood and adolescence (Eisenberg, Spinrad, \& Knafo-Noam, 2015). Prosocial behavior has been shown to be positively linked with desirable outcomes during adolescence, including self-esteem (Eisenberg et al., 2015), friendliness (Caprara, Barbaranelli, Pastorelli, Bandura, \& Zimbardo, 2000), and selflessness (Carlo, 2014); as well being negatively linked with harmful behaviors like aggression (Crick, 1996; Laible, McGinley, Carlo, Augustine, \& Murphy, 2014), suicidal ideation (Hall-Lande, Eisenberg, Christenson, \& Neumark-Sztainer, 2007), and association with delinquent peers (Carlo et al., 2014). While many of the conceptualizations and empirical explorations of prosocial behavior have treated this behavior as a general, unidimensional construct, more recent studies have begun to hone in on the multidimensional nature of this complex set of behaviors (Padilla-Walker \& Carlo, 2014). Two important dimensions that are emerging in prosocial behavior include different types of prosocial behavior (like helping in response to a request or helping in dire circumstances; Carlo et al., 2014), and how prosocial behavior differs as a function of the target of the behavior (e.g., strangers, friends, and family; PadillaWalker \& Christensen, 2011). Parents (usually mothers) have been highlighted as a significant influence in the socialization of prosocial behavior in children and adolescents. Given these advancements in the field, there is a need for nuanced longitudinal studies

This article was published Online First September 28, 2015.

Laura M. Padilla-Walker, Matthew G. Nielson, and Randal D. Day, School of Family Life, Brigham Young University.

Correspondence concerning this article should be addressed to Laura M. Padilla-Walker, School of Family Life, Brigham Young University, 2097 JFSB, Provo, Utah 84602. E-mail: laura_walker@byu.edu that examine how mothering and fathering impact prosocial behavior toward different targets. This study accomplishes that goal by (a) considering prosocial behavior as a function of target, (b) looking at both parental warmth and hostility on child outcomes, (c) considering the influence of both fathers and mothers, and (d) using a triangulation of sources including parent, child, and observational reports.

\section{Different Targets of Prosocial Behavior}

Although the target of prosocial behavior is rarely specified in existing research, when it is considered, meaningfully different patterns emerge. More specifically, people of all ages are more likely to help friends and family than strangers (Costin \& Jones, 1992; Fujisawa, Kutsukake, \& Hasegawa, 2008; Padilla-Walker \& Christensen, 2011), and adolescents report helping friends more than any other target (Güroğlu, van den Bos, \& Crone, 2014). One explanation for these differences is that helping behavior in a relationship looks different from when adolescents help those they do not know. Prosocial behavior toward strangers is more often motivated by dispositional traits (sympathy, self-regulation, etc.), (e.g., prosocial disposition; Eisenberg et al., 2002). In contrast, helping behavior within a relationship is likely motivated by an effort to preserve/maintain that relationship (Eberly \& Montemayor, 1998; Lewis, 2014), with prosocial disposition contributing, but to a lesser degree (Eisenberg et al., 2002). Indeed, relational approaches suggest that prosocial behavior toward family and friends is heavily affected by dynamics of a close relationship including frequent contact, a shared history, and anticipation of future interactions (Amato, 1990; Lewis, 2014). Research supports theory in finding that prosocial behavior in friendships is predicted by relationship quality among friends (Padilla-Walker, Fraser, Black, \& Bean, 2015), while the parent-child relationship is the most salient and consistent predictor of prosocial behavior toward family (PadillaWalker \& Christensen, 2011). Despite these differences in predictors, 
research has also found that regardless of target, the parent-child relationship is uniquely important in promoting both dispositional characteristics that lead to prosocial behavior, as well as prosocial behavior aimed at targets outside of the family (Padilla-Walker et al., 2015). Thus, while we acknowledge that relationships and dispositional characteristics likely influence targets of prosocial behavior differently, parenting seems to be influential to all targets of prosocial behavior, making it important to examine more carefully the influence of the parent-child relationship on prosocial behavior aimed at multiple targets.

\section{Parental Socialization of Prosocial Behavior}

One relevant theory for the strength of the parental influence on child behavior is social learning theory, suggesting that children will model behavior after the manner they see their parents interact with family members and others (Bandura, 1977). Relational theorists have extended this model by explaining that parent-child interactions are cyclical in that if children internalize the prosocial interactions of parents, the children's actions will become more prosocial, and parents will be among the beneficiaries of that prosocial behavior (Grusec \& Davidov, 2010; Grusec \& Goodnow, 1994). This may be especially true during adolescence, when interactions become much more egalitarian and reciprocal in nature, wherein if the parent is cooperative and warm in his or her responses to requests from the child, the child is in turn warm and cooperative (i.e., prosocial) toward the parent and others (e.g., mutual cooperation; Grusec \& Davidov, 2010; Kuczynski \& Hildebrandt, 1997). Alternatively, hostile interactions with parents lead to fewer adolescent prosocial behaviors toward parents and others because of a lack of the modeled behavior, potentially different relationship norms and expectations, and lower levels of perceived parental reciprocity.

\section{Parental Warmth/Support}

In relational research, warmth (i.e., support, responsiveness) is described as type of reward system that can motivate positive behavior (Macdonald, 1992) to the extent that parental warmth facilitates child imitation of and identification with parental behavior (Bandura, 1969), as well as a willingness to comply with parental requests and shared goals (Kuczynski \& Hildebrandt, 1997). A child whose parents employ warmth and who model prosocial behavior should be more likely to display prosocial behavior themselves, and research suggests that this is true (Eisenberg et al., 2015; Hastings, Utendale, \& Sullivan, 2007). Warm parenting has been linked with close relationships (Carlo, 2014), altruism (Carlo, McGinley, Hayes, \& Martinez, 2012; Eberly \& Montemayor, 1999), reported prosocial behavior (Domitrovich \& Bierman, 2001), and observed prosocial behavior (Carlo, 2014). Although it should be noted that other studies have found more mixed results in terms of the link between warmth and prosocial behavior, especially when prosocial behavior is defined as helping one in distress (Davidov \& Grusec, 2006).

When parental influences are analyzed separately, the gender of both parents and children often emerge as salient factors. For example, Eberly and Montemayor (1999) found that adolescents were more prosocial to their mothers because they were spending more time with them than with fathers (Eisenberg, 1983), and because on average, mothers provide more comfort than do fathers (Roberts, 1999). Warm mothering has been associated with perspective taking in children, daughters with more sympathy, and sons with less personal distress (Eisenberg \& McNally, 1993). The results for the influence of fathers on prosocial behavior is scarce, and existing research has found that fathering is not consistently associated with prosocial outcomes (Hart et al., 1992; PadillaWalker, Carlo, Christensen, \& Yorgason, 2012). Collectively, many in the field agree with Fortuna and Knafo (2014) that "mothers contribute more strongly than fathers to children's prosocial development" (p. 71), or that mothering promotes positive outcomes while fathering protects against problem behaviors (Day \& Padilla-Walker, 2009; Stolz, Barber, \& Olsen, 2005). While these statements may have merit, given the multidimensionality of both parenting and prosocial behavior, it is possible that fathering may influence different types (or targets) of prosocial behavior than does mothering.

\section{Parental Hostility}

Parental hostility, including parental displays of anger, frustration, and disappointment in children, as well as overt hostility (fighting, sarcasm, and emotional abuse) are associated with lower levels of prosocial behavior in children (Eisenberg et al., 1999; Hastings, Zahn-Waxler, Robinson, Usher, \& Bridges, 2000). Explanations for the connection between parental hostility and prosocial behavior suggest that if children feel a lack of care or concern from their parents, they may feel their actions to help others have no efficacy (Barber, Stolz, \& Olsen, 2005; Hastings et al., 2000), and they may have fewer models for prosocial behavior (Hastings, McShane, Parker, \& Ladha, 2007). Similarly, parents who are consistently faced with resistance from their children may increasingly withdraw from negative interactions and relinquish opportunities to improve their parenting (Pardini, Fite, \& Burke, 2008).

The relation between parental hostility and prosocial behavior is complex, affected by factors like the gender of parents (Crockenberg, Jackson, \& Langrock, 1996) and the genetic dispositions of parents and children (Elgar, Mills, McGrath, Waschbusch, \& Brownridge, 2007), but studies agree that verbal hostility is especially hard on adolescents (Muris, Meesters, Morren, \& Moorman, 2004) and that these effects carry across different nations and cultures (Barber et al., 2005). The children of verbally hostile mothers show lower peer acceptance (Domitrovich \& Bierman, 2001) and more aggression (Hart, Nelson, Robinson, Olsen, \& McNeilly-Choque et al., 1998), both of which have been implicated in lower levels of prosocial behavior. The limited number of studies that include fathers suggest that father hostility has a stronger negative effect on prosocial behavior than father warmth has a positive effect (Deković \& Janssens, 1992; Perez-Albeniz \& de Paul, 2004).

\section{Current Study}

The current study sought to fill a number of gaps in our understanding of how parenting might promote prosocial behavior during adolescence. First, we examined multiple targets of prosocial behavior (strangers, friends, family) to determine whether parenting was differentially associated with prosocial behavior toward different targets. We expected that parenting would be most 
strongly associated with prosocial behavior toward family, but based on existing research, expected it to promote prosocial behavior toward other targets as well. Second, we examined both parental warmth and parental hostility, and expected that parental warmth would promote prosocial behavior, whereas parental hostility would be negatively associated with prosocial behavior. Third, we examined both mothering and fathering to determine if there were differential effects based on parent gender, and expected that father hostility might be a better predictor of prosocial behavior than father warmth. Fourth, because relations between parenting and behavior have been found to be quite different as a function of reporter (Dyer, Day, \& Harper, 2014), we examined both warmth and hostility in a variety of ways, including, childreport, parent-report, and observations of parenting behavior based on videotaped parent-child interactions.

\section{Method}

\section{Participants and Procedures}

Participants for this study included 500 adolescents ( $M$ age at Time $2=12.34, S D=1.06,52 \%$ female $)$ and their parents $(M$ age mothers $=44.15, S D=6.17 ; M$ age fathers $=46.20, S D=6.17)$, taken from Times 2 and 3 of a longitudinal study that began in 2007 when the adolescents were an average of 11.5 years of age, and has followed them to adulthood. Time 2 and 3 were used because of the availability of observational reports of parenting. Time points were approximately 1 year apart, and longitudinal response rate was over $90 \%$. In terms of ethnicity, $67 \%$ were European American, 12\% African American, and 21\% reported being of mixed ethnicity. Nearly $20 \%$ of families reported an annual income of less than $\$ 40,000$ per year, while $30 \%$ reported an annual income of more than $\$ 100,000$ per year.

Research was approved by the sponsoring university's Institutional Review Board and appropriate consent was obtained from all family members. Each family member was paid $\$ 100$ for their participation. For the initial time point, families were randomly selected from targeted census tracts in a large northwestern city, and were identified using a purchased national telephone survey database (Polk Directories/InfoUSA). Families were interviewed in their homes, with each interview consisting of a video task and questionnaires completed by the child, mother, and father (initial response rate of eligible families was $61 \%$ ). For the video task, interviewers set up the camera in a separate room and left the room during the task. Tasks consisted of a 12-min interaction between the mother and child and a 12-min interaction between the father and child. During the mother-child and father-child interaction task, the target child and his or her parent discussed a number of issues presented on discussion cards (e.g., "What do you think have been your child's biggest accomplishments in the last year?" and "What does your mom/dad do when you do something she/he doesn't like?"). These video tasks followed the protocol established by the Iowa State Coding Lab and were coded using the Iowa Family Interaction Rating Scales (Melby et al., 1998; see Padilla-Walker, Harper, \& Bean, 2011 for more information on procedures).

\section{Measures}

Parenting. Parenting was measured at Time 2 using both questionnaires and observational ratings. First, mothers and fathers reported on their own parenting, and adolescents reported on their parents' warmth/support and verbal hostility using two subscales of the Parenting Styles and Dimensions Questionnaire-Short Version (PSDQ; Robinson, Mandleco, Olsen, \& Hart, 2001). Adolescents, mothers, and fathers were asked how often their parents (they) did certain behaviors characteristic of warmth (5 items, e.g., "My parent is/I am responsive to my/my child's feelings and needs") and verbal hostility (4 items, e.g., "My parent/I yells or shouts when I/my child misbehaves"). Responses ranged on a 5-point Likert scale from 1 (never) to 5 (always), with higher scores indicating higher levels of parenting. Latent variables were created using the individual items to create both mothers' (warmth: $\alpha=.78$; hostility: $\alpha=.70$ ) and fathers' (warmth: $\alpha=.78$; hostility: $\alpha=.71$ ) self-reported parental warmth and hostility, as well as child-reported parental warmth and hostility for both mothers (warmth: $\alpha=.82$; hostility: $\alpha=.74$ ) and fathers (warmth: $\alpha=.83$; hostility: $\alpha=.75$ ).

Parenting was also measured from dyadic interaction scales, which were created by coding the observed interactive in-home video tasks. Specialized coders watched each video task and coded for a variety of individual and dyadic codes. Interrater reliability was assessed via ICC (Choukalis, Melby, \& Lorenz, 2000). Parental warmth/support was assessed by creating a latent variable using three codes for mothers and fathers (warmth, listener responsiveness, and communication; interrater reliability for mothers = $.82, .84, .89$, interrater reliability for fathers $=.80 .82, .88$ ) that were all aspects of warmth/support and mirrored the items used in the questionnaire. On a scale ranging from 1 (not at all characteristic) to 9 (mainly characteristic), parental warmth was assessed by the degree to which the parent expressed care, concern, support, and encouragement and built on these behaviors, nonverbal and verbal responsiveness that indicated validation and attentiveness, and the ability to communicate one's point of view and demonstrate consideration of the child's point of view. Parental hostility was also assessed by creating a latent variable using three codes for mothers and fathers (hostility, escalate hostility, and reciprocate hostility; interrater reliability for mothers $=.86, .92, .98$, interrater reliability for fathers $=.85, .92, .97$ ) that were indicative of hostility similar to the verbal hostility in the questionnaire items. On a scale ranging from 1 (not at all characteristic) to 9 (mainly characteristic), negative parenting was assessed by the degree to which the parent expressed hostile, angry, critical, disapproving, rejecting, or contemptuous behavior directed toward the child, as well as the parent's tendency to escalate their hostile behavior and reciprocate hostility from the child.

Prosocial behavior. Adolescents' prosocial behavior was measured at Time 2 and 3 using both questionnaire and observational ratings. First, prosocial behavior was measured using a modified version of the kindness and generosity subscale of the Values in Action Inventory of Strengths (Peterson \& Seligman, 2004). The original measure was designed to assess behaviors toward strangers $(9$ items, $\alpha$ Time $2=.85$, Time $3=84$; e.g., "I help people I don't know, even if it's not easy for me"). Similar items were adapted to assess prosocial behavior toward friends ( 9 items, $\alpha$ Time $2=.90$, Time $3=.93$ e.g., "I go out of my way to cheer up my friends") and 
family ( 9 items, $\alpha$ Time $2=.92$, Time $3=.93$; e.g., "I really enjoy doing small favors for my family") on a 5-point Likert scale ranging from 1 (not like me at all) to 5 (very much like me). Mean scales of each target of prosocial behavior were used for all analyses.

Prosocial behavior was also assessed using two codes (one for prosocial behavior toward mother, one for prosocial behavior toward father) from dyadic interaction scales discussed above (prosocial behavior toward mother, interrater reliability at Time $2=.81$; Time $3=.86$; prosocial behavior toward father, interrater reliability at Time $2=.83$; Time $3=.89$ ). On a scale ranging from 1 (not at all characteristic) to 9 (mainly characteristic), prosocial behavior was assessed by the degree to which the child demonstrated helpfulness, sensitivity, cooperation, sympathy, and respectfulness toward the other individual (mother or father) in the interaction. Both verbal and nonverbal behavior was assessed, so prosocial behavior could be represented by a child being kind to their parent during the interaction or referring to them in a positive way (e.g., as a hero), versus a child who was very indifferent or was making derogatory comments about the parent. Other examples include adolescents who made references to helping their parent or to being cooperative or empathic.

\section{Analysis Plan}

In order to examine longitudinal relations between parenting and prosocial behavior, structural equation models were conducted using AMOS software (Arbuckle, 2010), with separate models for parental warmth and verbal hostility. Models were conducted sepa- rately due to collinearity that was present when putting the two types of parenting together and because of low power in a single full model. Model fit was considered acceptable if comparative fit index (CFI) $>$ .90 , standardized root-mean-square residual (SRMR) $<.08$, and root-mean-square error of approximation (RMSEA) $<.08$ (Little, 2013). First, measurement models were conducted to determine factor loadings of latent variables and measurement model fit. Latent variables included all parenting variables, but prosocial behaviors were manifest variables using scale mean scores. Prosocial behaviors were measured as mean scores because we did not have adequate power to include all variables as latent variables. Covariances were added between all variables, and error covariances were included between corresponding child-reported indicators of mother and father parenting. Next, structural models were conducted. Models for both warmth and hostility consisted of latent variables at Time 2 for mother and father self-reported parenting, child-reports of mothers' and fathers' parenting, and observations of both mothers' and fathers' parenting. Outcome variables consisted of adolescents' self-reported prosocial behavior toward strangers, friends, and family, as well as observations of adolescents' prosocial behavior toward mother and father. In structural models, parenting at Time 2 was regressed on adolescents' prosocial behavior at Time 3, and initial levels of prosocial behavior were controlled for at Time 2 . In addition, adolescent gender, age, and ethnicity were used as control variables (see Figure 1 for proposed model). It is of note that missing data were minimal $(<5 \%)$, and we used the Full Information Maximum Likelihood feature of AMOS to handle missing data.

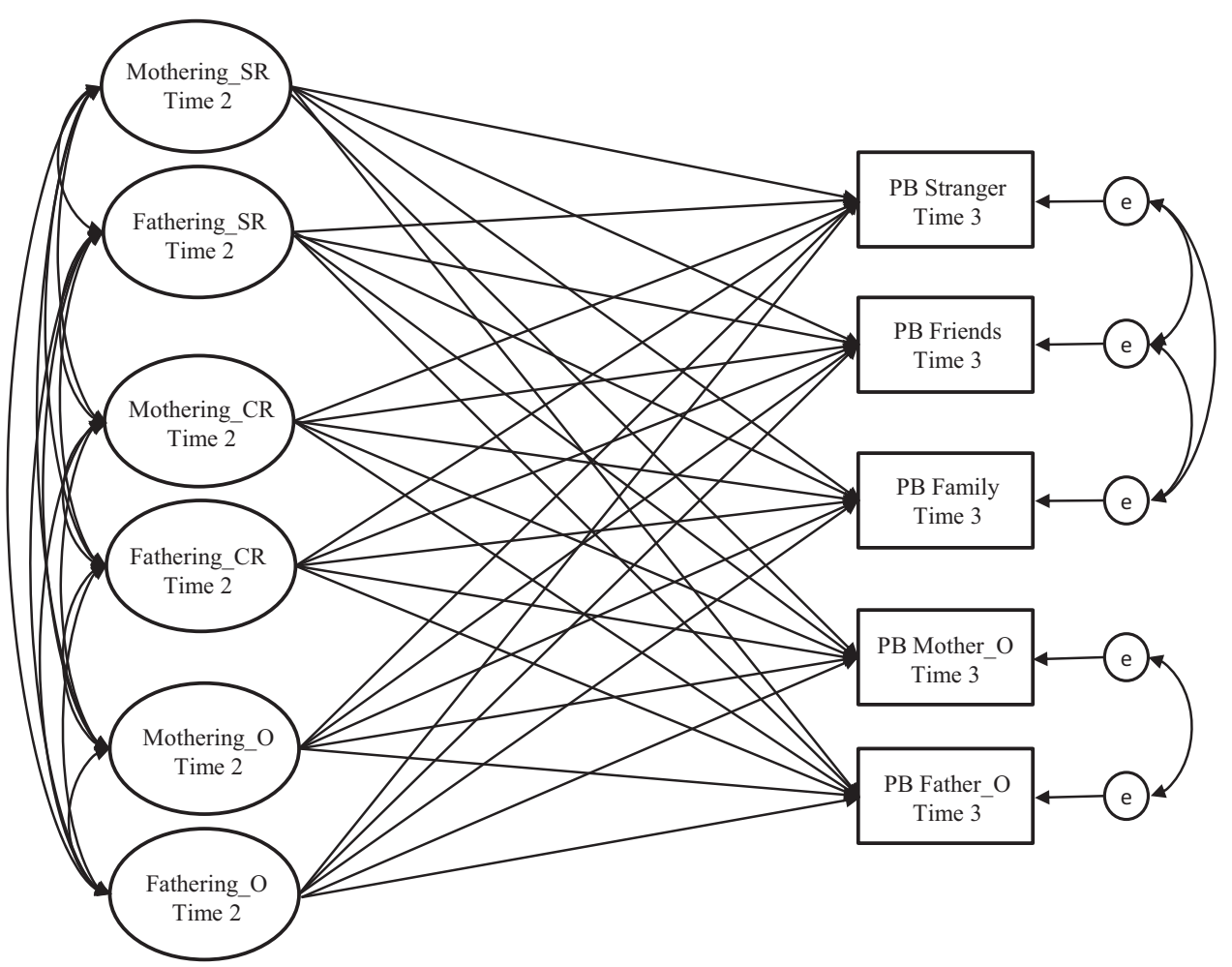

Figure 1. Proposed structural equation model. $\mathrm{SR}=$ self-report; $\mathrm{CR}=$ child-report; $\mathrm{O}=$ observed; $\mathrm{PB}=$ prosocial behavior. All Time 3 behaviors are controlled for at Time 2. Child gender, age, and ethnicity are also controlled at Time 2. 


\section{Results}

\section{Descriptive Statistics and Correlations}

$T$ tests were conducted to determine gender and ethnicity differences on variables of interest. In terms of gender, results revealed that girls $(M=4.11)$ reported higher levels of mother warmth than did boys $(M=3.92 ; t(476)=2.69, p<.01)$, and girls reported higher levels than boys of prosocial behavior toward strangers $(3.26$ vs. $2.95 ; t(457)=4.54, p<.001)$, friends $(4.51$ vs. $3.99 ; t(457)=9.14, p<.001)$, and family $(4.14$ vs. $3.82 ; t(457)=$ 4.27, $p<.001)$. Observations of prosocial behavior toward father were also higher for girls than boys (5.30 vs. 4.88; $t(298)=3.20$, $p<.01)$. In terms of ethnicity, European American $(M=4.12)$ adolescents reported higher levels of mother warmth than did other ethnicities $(M=3.83 ; t(466)=3.90, p<.001)$, and coders observed higher levels of mother warmth in European American mothers $(M=5.53)$ compared with other ethnicities $(M=4.96$; $t(447)=6.07, p<.001)$. European American $(M=2.13)$ adolescents reported lower levels of mother verbal hostility than did other ethnicities $(M=2.36 ; t(466)=-2.84, p<.01)$, and coders observed higher levels of prosocial behavior toward mothers for European American teens (5.17 vs. 4.78, $t(405)=3.33, p<.001)$.

Means, standard deviations, and correlations of all variables are presented in Tables 1 and 2. It should be noted that parenting was more strongly associated with prosocial behavior toward family than toward strangers and friends. Additionally, fathering seemed to be less consistently associated with prosocial behavior than mothering.

\section{Longitudinal Associations Between Parenting and Prosocial Behavior}

First, a measurement model was analyzed for each model. For the warmth measurement model, latent variables were created using the individual items to create both mothers' (factor loadings .57-.70) and fathers' (factor loadings .63-.68) self-reported parental warmth, as well as child-reported parental warmth for both mothers (factor loadings .61-.83) and fathers (factor loadings $.64-.72$ ) and observations of mother (factor loadings .47-.78) and father (factor loadings .32-.87) warmth. The parental warmth measurement model had good model fit, $\chi^{2}(479)=690.28, p<$ $.001 ; \mathrm{CFI}=.97, \mathrm{SRMR}=.05, \mathrm{RMSEA}=.03[.025, .035]$, with all factor loadings $>.40$ save one (one item on observed father warmth).

For the hostility measurement model, latent variables were created using the individual items to create both mothers' (factor loadings .38-.77) and fathers' (factor loadings .39-.80) selfreported parental hostility, as well as child-reported parental hostility for both mothers (factor loadings .48-.75) and fathers (factor loadings .52-.78) and observations of mother (factor loadings $.60-.80$ ) and father (factor loadings .65-.73) hostility. All latent variables were correlated with one another. The parental hostility measurement model also had adequate fit, $\chi^{2}(348)=740.36, p<$ $.001, \mathrm{CFI}=.93, \mathrm{SRMR}=.07, \mathrm{RMSEA}=.05[.043, .052]$, with all factor loadings $>.40$ save two (one for mother and one for father self-reported hostility).

Next, structural models were analyzed. For the parental warmth model, there was good model fit, $\chi^{2}(565)=837.54, p<.001$, $\mathrm{CFI}=.96, \mathrm{SRMR}=.05, \mathrm{RMSEA}=.03[.027, .035]$. Results suggested that mother warmth (self-reported) was positively associated with prosocial behavior toward family, and that mother warmth (child-reported) was positively associated with observed prosocial behavior toward mother (see Table 3). Father warmth (observed) was positively associated with prosocial behavior toward friends, while father warmth (child-reported) was positively associated with observed prosocial behavior toward father. Of note, self-reported mother and father warmth were positively correlated with Time 2 prosocial behavior toward all targets except strangers and friends ( $r$ ranged from .15-.26, $p<.05$ ), childreported mother and father warmth were positively correlated with Time 2 prosocial behavior toward all targets $(r$ ranged from $.16-.57)$, and observations of mother and father warmth were correlated with Time 2 prosocial behavior toward all targets $(r$ ranged from .12-.30). Endogenous error correlations were included between all self-reported prosocial behaviors $(r$ ranged from $.40-.47)$ and between observed prosocial behaviors $(r=$ .24). In terms of controls, gender (males had the higher coded value) was negatively associated with prosocial behavior toward strangers $(\beta=-.07, p<.05)$, friends $(\beta=-.21, p<.001)$, and fathers (observed; $\beta=-.12, p<.05$ ); and adolescents' age was

Table 1

Descriptive Statistics and Correlations Between Parental Warmth/Support and Prosocial Behavior

\begin{tabular}{|c|c|c|c|c|c|c|c|c|c|c|c|}
\hline & 1 & 2 & 3 & 4 & 5 & 6 & 7 & 8 & 9 & 10 & 11 \\
\hline 1. MWarmth_SR_2 & - & & & & & & & & & & \\
\hline 2. FWarmth SR 2 & $.31^{* * * * *}$ & - & & & & & & & & & \\
\hline 3. MWarmth_CR_2 & $.24^{* * * * *}$ & $.26^{* * * * *}$ & - & & & & & & & & \\
\hline 4. FWarmth_CR_2 & $.15^{* * *}$ & $.27^{* * * *}$ & $.73^{* * * *}$ & - & & & & & & & \\
\hline 5. MWarmth_O_2 & $.13^{* * *}$ & .11 & $29^{* * * *}$ & $.25^{\text {****** }}$ & - & & & & & & \\
\hline 6. FWarmth_O_2 & $.19^{\text {**** }}$ & $.21^{* * * *}$ & $20^{* * * *}$ & $.20^{* * *}$ & $.22^{* * * * *}$ & - & & & & & \\
\hline 7. PB Strangers_3 & $.12^{* * *}$ & .09 & $.34^{* * * *}$ & $.28^{* * * *}$ & $.15^{* *}$ & $.13^{*}$ & - & & & & \\
\hline 8. PB Friends 3 & $.11^{*}$ & .09 & $32^{\text {***** }}$ & $.28^{* * * *}$ & $.13^{* * *}$ & $.19^{* *}$ & $.60^{\text {***** }}$ & - & & & \\
\hline 9. PB Family_3 & $.24^{* * * *}$ & $.17^{* * *}$ & $.40^{* * * *}$ & $.34^{* * * *}$ & .08 & $.18^{* * *}$ & $.55^{\text {***** }}$ & $.58^{\text {****** }}$ & - & & \\
\hline 10. PB Mother O 3 & $.11^{*}$ & .03 & $.25^{\text {***** }}$ & $.16^{* * *}$ & $.17^{* * * * *}$ & .08 & $.20^{* * * * *}$ & $.23^{* * * * *}$ & $.26^{* * * * * *}$ & - & \\
\hline 11. PB Father_O_3 & .10 & .11 & $.23^{* * * *}$ & $.23^{\text {***** }}$ & $.13^{*}$ & .11 & $.19^{* *}$ & $.25^{* * * * *}$ & $.28^{* * * * *}$ & $.36^{* * * * *}$ & - \\
\hline$M(S D)$ & $4.31(.47)$ & $4.01(.57)$ & $4.02(.80)$ & $3.81(.86)$ & $5.34(.97)$ & $5.22(.93)$ & $3.11(.74)$ & $4.26(.66)$ & $3.98(.81)$ & $5.03(1.13)$ & $5.10(1.14)$ \\
\hline
\end{tabular}

Note. $\quad \mathrm{M}=$ mother; $\mathrm{F}=$ father; $\mathrm{SR}=$ self-report; $\mathrm{CR}=$ child-report; $\mathrm{O}=$ observed; $\mathrm{PB}=$ prosocial behavior; $2=$ Time $2 ; 3=$ Time 3 .

${ }^{*} p<.05 . \quad{ }^{* *} p<.01 . \quad{ }^{* * *} p<.001$. 
Table 2

Descriptive Statistics and Correlations Between Parental Hostility and Prosocial Behavior

\begin{tabular}{|c|c|c|c|c|c|c|c|c|c|c|c|}
\hline & 1 & 2 & 3 & 4 & 5 & 6 & 7 & 8 & 9 & 10 & 11 \\
\hline 1. MHostility_SR_2 & - & & & & & & & & & & \\
\hline 2. FHositlity_SR_2 & $.25^{* * * *}$ & - & & & & & & & & & \\
\hline 3. MHostility_CR_2 & $.29^{* * * *}$ & $.24^{* * * * *}$ & - & & & & & & & & \\
\hline 4. FHostility_CR_2 & $.19^{* * * *}$ & $.28^{* * * *}$ & $.71^{* * * * *}$ & - & & & & & & & \\
\hline 5. MHostility_O_2 & $.16^{* * * *}$ & .08 & $.19^{* * * * *}$ & $.15^{* *}$ & - & & & & & & \\
\hline 6. FHostility_O_2 & $.14^{*}$ & $.16^{* *}$ & .01 & .08 & .07 & - & & & & & \\
\hline 7. PB Strangers_3 & $-.14^{* * *}$ & -.03 & $-.12^{*}$ & -.05 & $-.15^{* *}$ & -.08 & - & & & & \\
\hline 8. PB Friends_3 & $-.13^{* * *}$ & -.07 & $-.14^{* * *}$ & $-.16^{* * * *}$ & $-.10^{*}$ & -.04 & $.60^{\text {******* }}$ & - & & & \\
\hline 9. PB Family_3 & $-.13^{* *}$ & -.01 & $-.13^{* * *}$ & $-.11^{*}$ & -.03 & -.08 & $.55^{* * * *}$ & $.58^{* * * *}$ & - & & \\
\hline 10. PB Mother_O_3 & $-.12^{*}$ & $-.12^{*}$ & $-.17^{* * * *}$ & $-.13^{*}$ & $-.16^{* * *}$ & $-.12^{*}$ & $.20^{* * * *}$ & $.23^{* * * *}$ & $.26^{* * * *}$ & - & \\
\hline 11. PB Father_O_3 & -.09 & -.06 & $-.17^{* * *}$ & $-.17^{* *}$ & -.03 & -.10 & $.19^{* * * *}$ & $.25^{* * * *}$ & $.28^{* * * *}$ & $.36^{* * * *}$ & - \\
\hline$M(S D)$ & $2.15(.57)$ & $2.14(.58)$ & $2.20(.84)$ & $2.19(.86)$ & $1.21(.49)$ & $1.13(.34)$ & $3.12(.74)$ & $4.26(.66)$ & $3.98(.81)$ & $5.03(1.13)$ & $5.1(1.14)$ \\
\hline
\end{tabular}

Note. $\mathrm{M}=$ mother; $\mathrm{F}=$ father; $\mathrm{SR}=$ self-report; $\mathrm{CR}=$ child-report; $\mathrm{O}=$ observed; $\mathrm{PB}=$ prosocial behavior; $2=$ Time $2 ; 3=$ Time 3 .

${ }^{*} p<.05 . \quad{ }^{* *} p<.01 . \quad{ }^{* * * *} p<.001$.

positively associated with observed prosocial behavior toward mothers $(\beta=.10, p<.05)$. Stability paths were all significant, with Time 2 prosocial behavior toward strangers $(\beta=.60, p<$ $.001)$, friends $(\beta=.44, p<.001)$, family $(\beta=.51, p<.001)$, mother $(\beta=.26, p<.001)$, and father $(\beta=.27, p<.001)$, all associated with the corresponding Time 3 prosocial behavior.

For the parental hostility structural model, results suggested adequate model fit, $\chi^{2}(422)=878.32, p<.001$, CFI $=.92$, SRMR $=.07$, RMSEA $=.05$ [.042-.051]. Results suggested that father hostility (child-reported) was negatively associated with prosocial behavior toward friends, and that father hostility (observed) was negatively associated with prosocial behavior toward strangers, family, mother (observed), and father (observed, marginally significant). Of note, self-reported mother hostility at Time 2 was negatively correlated with Time 2 prosocial behavior toward all targets $(r$ ranged from $-.15--.28, p<.05)$; while fathers' self-reported hostility was not significantly associated with any target of prosocial behavior. Child-reported mother and father hostility were negatively correlated with Time 2 prosocial behavior toward all targets $(r$ ranged from $-.11--.34, p<.05)$. Observations of mother hostility were only negatively correlated with observed prosocial behavior toward mother at Time 2, $r=-.24, p<.01$, while observations of father hostility were negatively correlated with Time 2 prosocial behavior toward all targets $(r$ ranged from $-.12--.26, p<.05)$. Endogenous error correlations were included between all self-reported prosocial behaviors ( $r$ ranged from .41-.46) and between observed prosocial behaviors $(r=.23)$. In terms of controls, gender (males had the higher coded value) was negatively associated with prosocial behavior toward strangers $(\beta=-.09, p<.05)$, friends $(\beta=-.21, p<.001)$, family $(\beta=-.08, p<.05)$, and fathers (observed; $\beta=-.14, p<.05$ ); ethnicity (nonwhite had higher coded value) was negatively associated with observed prosocial behavior toward mother $(\beta=-.11, p<.05)$, and adolescents' age was positively associated with observed prosocial behavior toward mothers $(\beta=.12, p<.05)$.

\section{Discussion}

The purpose of the current study was to examine the influence that both parental warmth and hostility might have on prosocial behavior toward multiple targets. Results indicated that mother warmth was associated with adolescents' prosocial behavior toward family and mothers, and that father warmth was associated with prosocial behavior toward friends and fathers. In addition, mother hostility was not associated with any prosocial outcomes while father hostility was negatively associated with prosocial behavior toward family, friends, strangers, mothers, and fathers. While recent arguments have been raised suggesting fathering and mothering influences children in similar ways (Fagan, Day, Lamb, \& Cabrera, 2014), the current findings join a number of additional studies suggesting that fathering and mothering may be differentially related to adolescent outcomes, with particular emphasis on prosocial behavior. It was also clear from our findings that the reporter of parenting behavior had a significant impact on the pattern of results.

\section{Parental Warmth}

Previous research on parenting consistently validates social learning theory by indicating the impact of parental warmth and support on prosocial outcomes (Eberly \& Montemayor, 1998; Hastings, McShane et al., 2007; Lewis, 2014). Our study is consistent with these findings and suggests that positive mothering was directly and longitudinally related to prosocial behavior toward the family generally and prosocial behavior toward mothers specifically, and positive fathering was directly related to prosocial behavior toward fathers. While the link between positive fathering and prosocial behavior has not been commonly found in past research, and indeed, research on fathers' interactions with teens is scant at best, this study supports the need for research further delineating the role of men in the positive socialization of adolescents. It is particularly helpful to know that relationship strength between fathers and their children may be facilitated through increased parental warmth when combined with parents (especially fathers) modeling positive behavior. Based on our findings here, we suggest that future research examine the multiplicative relationships among mothers' and fathers' parenting and various forms and targets of prosocial development (Pleck, 2007).

Although our findings supported the link between positive parenting and prosocial behavior toward family, results also suggested a link between positive fathering and prosocial behavior toward 
Table 3

Mothers' and Father's Warmth/Support and Hostility Predicting Prosocial Behavior

\begin{tabular}{|c|c|c|c|c|c|c|}
\hline & \multicolumn{3}{|c|}{$\begin{array}{c}\text { Warmth/support } \\
\text { model }\end{array}$} & \multicolumn{3}{|c|}{ Hostility model } \\
\hline & $\beta$ & $b$ & $S E$ & $\beta$ & $b$ & $S E$ \\
\hline Mother SR on PB stranger & .09 & $.16^{\dagger}$ & .09 & -.03 & -.03 & .07 \\
\hline Mother SR on PB friend & .06 & .10 & .09 & -.10 & -.09 & .06 \\
\hline Mother SR on PB family & .11 & $.24^{*}$ & .11 & .03 & .03 & .08 \\
\hline Mother SR on PB mother obs & .04 & .11 & .19 & .03 & .05 & .14 \\
\hline Mother SR on PB father obs & .01 & .03 & .22 & -.05 & -.09 & .16 \\
\hline Father SR on PB stranger & -.05 & -.08 & .10 & -.01 & -.02 & .12 \\
\hline Father SR on PB friend & -.04 & -.07 & .09 & .04 & .07 & .11 \\
\hline Father SR on PB family & -.05 & -.09 & .11 & -.01 & -.03 & .14 \\
\hline Father SR on PB mother obs & -.03 & -.09 & .19 & -.02 & -.08 & .23 \\
\hline Father SR on PB father obs & .03 & .07 & .20 & .08 & .27 & .24 \\
\hline Mother CR on PB stranger & .09 & .10 & .08 & -.06 & -.05 & .06 \\
\hline Mother CR on PB friend & .03 & .03 & .08 & .03 & .02 & .05 \\
\hline Mother CR on PB family & .12 & .15 & .10 & .01 & .00 & .07 \\
\hline Mother CR on PB mother obs & .20 & $.36^{*}$ & .17 & -.18 & $-.23^{\dagger}$ & .12 \\
\hline Mother CR on PB father obs & -.05 & -.09 & .19 & -.09 & -.11 & .13 \\
\hline Father CR on PB stranger & .04 & .04 & .07 & -.01 & -.10 & .06 \\
\hline Father $\mathrm{CR}$ on $\mathrm{PB}$ friend & .11 & .10 & .06 & -.16 & $-.12^{*}$ & .05 \\
\hline Father CR on PB family & .05 & .06 & .08 & -.08 & -.08 & .06 \\
\hline Father CR on PB mother obs & .00 & .00 & .14 & -.04 & -.05 & .11 \\
\hline Father CR on $\mathrm{PB}$ father obs & .21 & $.33^{*}$ & .15 & -.13 & -.18 & .12 \\
\hline Mother obs on PB stranger & .00 & .00 & .05 & .00 & .00 & .05 \\
\hline Mother obs on PB friend & .00 & .00 & .05 & .05 & .05 & .05 \\
\hline Mother obs on PB family & -.04 & -.05 & .06 & .00 & .00 & .06 \\
\hline Mother obs on PB mother obs & .03 & .05 & .11 & -.04 & -.06 & .10 \\
\hline Mother obs on PB father obs & .05 & .08 & .13 & .03 & .05 & .11 \\
\hline Father obs on PB stranger & .03 & .04 & .08 & -.14 & $-.19^{* *}$ & .07 \\
\hline Father obs on PB friend & .13 & $.19^{*}$ & .08 & .00 & .00 & .07 \\
\hline Father obs on PB family & .08 & .14 & .09 & -.12 & $-.19^{*}$ & .08 \\
\hline Father obs on PB mother obs & .05 & .12 & .16 & -.18 & $-.39^{* * *}$ & .15 \\
\hline Father obs on PB father obs & -.02 & -.06 & .17 & -.13 & $-.28^{\dagger}$ & .15 \\
\hline
\end{tabular}

Note. $\mathrm{PB}=$ prosocial behavior; $\mathrm{SR}=$ self-report; $\mathrm{CR}=$ child-report; obs $=$ observed. All parenting variables are at Time 2; all prosocial behaviors are at Time 3. Prosocial behaviors are controlled for at Time 2, as well as child gender, age, and ethnicity. Model fit for the warmth/ support model: $\chi^{2}(565)=837.54, p<.001$, comparative fit index $(\mathrm{CFI})=$ .96 , standardized root-mean-square residual $(\mathrm{SRMR})=.05$, root-meansquare error of approximation (RMSEA) $=.03$. Model fit for the hostility model: $\chi^{2}(422)=878.32, \mathrm{CFI}=.92$, SRMR $=.07$, RMSEA $=.05$.

${ }^{\dagger} p<.08$. ${ }^{*} p<.05 .{ }^{* * *} p<.01$.

friends. Research on young children has found that children whose fathers discussed prosocial behavior with them were more prosocial at school with their peers (Hastings, McShane et al., 2007), and another study found that mother warmth was significantly associated with prosocial behavior toward friends (Padilla-Walker et al., 2015), but did not consider the role of fathers. Past research has supported the notion that fathers may see their role as providing some type of entrée and introduction to the outside world (Pleck, 2010), and friends may be the first of many nonfamily members one will eventually encounter. The current study builds on this research to suggest that during adolescence there might also be something unique about the role of fathers and prosocial behavior toward peers, though more research is clearly needed in this regard.

Whereas parental hostility was negatively linked with prosocial behavior toward all targets, parental warmth was only related to prosocial behavior toward parents and friends, and there were few consistent significant findings across reporters. Given the mixed findings in other studies regarding parental warmth (Davidov \& Grusec, 2006), one potential explanation is that while controlling parenting remains influential throughout adolescence, parental warmth may show less and less of a direct influence on children's behavior over time (Moilanen, Rasmussen, \& Padilla-Walker, 2015). This waning of the direct effect of parental warmth may not be unexpected given the development of autonomy and independence that occurs during adolescence (Steinberg \& Silk, 2002), and may be indicative of increasing indirect effects of parenting as children develop strong values and characteristics that are then directly associated with behavior (Padilla-Walker, 2014). This finding might also be attributable to the relative stability of adolescent prosocial behavior (Carlo, 2014; Padilla-Walker et al., 2012), in that adolescents' prosocial behavior, especially in the context of warm parenting, is relatively stable. This might particularly be the case in warm and reciprocal relationships where cooperative norms have been established and are relatively well functioning; whereas in a hostile or unpredictable relationship, norms might be less well-established and more open to change and fluctuations in behavior. Indeed, given theoretical assumptions that the influence of bad experiences outweigh the influence of good experiences (Baumeister et al., 2001), it is not unexpected that parental warmth would become less directly important while a negative parental influence like hostility would remain consistently influential.

\section{Parental Hostility}

It is well established that negative parenting, or parenting characterized by harshness, restriction, and displays of anger, frustration, and disappointment in children is connected with higher levels of negative outcomes and lower levels of positive outcomes for teens (e.g., Barber et al., 2005). The current findings are consistent with existing research, but highlight the unique role of fathers' negative parenting on adolescents' prosocial behavior. The current study indicate that negative fathering seems to have more of a negative influence than negative mothering because fathering was negatively associated with adolescents' prosocial behavior toward all targets, while negative mothering was not related to any prosocial outcomes. Research suggests that findings for father negativity that are not mirrored by mother negativity include lower prosocial behavior for children (particularly for sons) with fathers who are depressed (Elgar et al., 2007) and who encourage emotional regulation and suppression of emotions (Roberts, 1999). Thus, current findings build on a small number of studies suggesting the salience of father hostility on child outcomes.

Past research suggests that fathers have little positive influence on adolescent prosocial behavior (e.g., Fortuna \& Knafo, 2014), that fathers' influence is corrective or regulatory (Roberts, 1999) and that fathers are more strongly related to the absence of problem behavior (Day \& Padilla-Walker, 2009). The current findings did lend support to the idea that positive fathering is not as strong or consistent as the influence of negative fathering on adolescents' prosocial behaviors. Hasting, McShane et al. (2007) reasoned that one explanation for these outcomes is that perhaps fathers stay out of interactions that are going well, and only intercede when they feel correction is needed. Cleary the role of fathers in the positive development of their teens is a gap in the literature that needs to be 
addressed further, especially with an eye to multidimensionality of both fathering and prosocial behavior.

\section{Influence of Reporter}

The majority of previous studies conducted on parenting during adolescence have relied on parent (usually mother) reports or mixed parent and child reports, with few father-reported or observational reports of parenting. However, using data from a triad of sources, including observational coding, provides us with a richer picture about what might be occurring in the parent-child relationship during adolescence. Indeed, the current study's selfreported findings were similar to existing cross-sectional findings suggesting the primary importance of mothers in the development of prosocial behavior (Day \& Padilla-Walker, 2009; PadillaWalker \& Christensen, 2011; Stolz et al., 2005), and finding relatively few direct effects (Moilanen et al., 2015). However, many of the links between fathering and adolescent behaviors were found in the current study based on the observational codes of fathering behavior, which begs the question of what we may be capturing with observational measures that are not represented in self-reported behaviors, particularly for fathers.

A fascinating aspect of family life is the alternate perceptions of reality that differ according to the reporter (Broderick, 1993), and indeed, there were only modest correlations between different reports of parenting in the current study. Holmbeck, Li, Schurman, Friedman, and Coakley (2002) articulated that these individual perceptions of reality are created by personality and cognitive characteristics that color the way an individual experiences life. They posit that observational methods of reporting are able to eliminate some of those personal characteristic biases and extract shared properties. A recent study by Dyer, Day, and Harper (2014) examined shared and unique perceptions of father engagement and warmth and found that mothers' perceptions of warmth overlapped more with shared perspectives than did father warmth. Thus, it may be that fathers' have a unique perception of their own parenting that is not as representative of what teens are experiencing. Another study examined measurement invariance of father involvement using mother, father, child, and observed reports of the same measure of father involvement and found that of the three reporters, the adolescent report was the most strongly related to the observed report (Dyer, Day, \& Harper, 2013). They hypothesized that perhaps the adolescents report on a more global father-child relationship than do parents, or that they may be a less biased source than their parents. The current study found few consistent patterns across reporters, suggesting that perhaps a very different view of parenting is captured by self-report, child-report, and observations. Taken together, these findings indicate that future studies on the socialization of adolescent prosocial behavior would do well to include observational data of parent-child interactions, especially as they relate to fathering behaviors.

\section{Limitations, Conclusions, and Future Directions}

The current study was not without limitations. The sample was mainly European American middle class, thus the data may not be generalizable to other populations of interest. Future research should also examine single-parent families with nonresidential fathers to determine if fathers have the same influence on prosocial behavior across contexts. Another important future direction is examining the role of child gender as well as parent gender. Though parenting during adolescence has not consistently been found to differentially impact behavior as a function of the child's gender (Steinberg \& Silk, 2002), some studies have found that gender potentially influences parent-child interactions during childhood (Hastings, Utendale et al., 2007), and future research should continue to explore this possibility.

Although the study had the strength of a longitudinal design, direction of effects could not be determined. Indeed, theory has long supported (Grusec \& Goodnow, 1994), and a growing body of research suggests that children's prosocial behavior has a particularly salient role on parenting during adolescence (PadillaWalker et al., 2012), and it is likely that a bidirectional study would yield reciprocal relations that might be informative. Future research should also consider not only direct effects of parenting on adolescents' behavior, but should also consider indirect effects, as parenting may be less consistently directly associated with child outcomes during adolescence (Padilla-Walker, 2014), and may instead promote child characteristics (e.g., sympathy, selfregulation, values) that in turn impact behavior. This may have been a key reason for the relatively few direct effects found in the current study, and is an important direction for future research.

Despite these limitations, the current study provides useful insights into the multidimensional nature of both parenting and prosocial behavior. While confirming existing studies suggesting the role of mother warmth on prosocial behavior toward family, the current study also highlighted father warmth as a potentially important correlate of prosocial behavior toward friends. Findings also underscored the role of father hostility in reducing levels of prosocial behavior, with one potential suggestion being a need to encourage fathers to be more involved in the positive interactions in their children's lives rather than acting primarily as a disciplinarian. Finally, the current study is an important step in our understanding of multiple reporters of parenting during adolescence and highlights the salience of observations of parent-child interactions, especially for fathers.

\section{References}

Amato, P. R. (1990). Personality and social network involvement as predictors of helping behavior in everyday life. Social Psychology Quarterly, 53, 31-43. http://dx.doi.org/10.2307/2786867

Arbuckle, J. L. (2010). Amos 19.0 user's guide. Chicago, IL: SPSS, Amos Development Corporation.

Bandura, A. (1969). Principles of behavior modification. Oxford, England: Holt, Rinehart, \& Winston.

Bandura, A. (1977). Social learning theory. Englewood Cliffs, NJ: Prentice Hall.

Barber, B. K., Stolz, H. E., \& Olsen, J. A. (2005). Parental support, psychological control, and behavioral control: Assessing relevance across time, culture, and method. Monographs of the Society for Research in Child Development, 70, 1-137.

Baumeister, R. F., Bratslavsky, E., Finkenauer, C., \& Vohs, K. D. (2001). Bad is stronger than good. Review of General Psychology, 5, 323.

Broderick, C. B. (1993). Understanding family process: Basics of family systems theory. Newbury Park, CA: Sage.

Caprara, G. V., Barbaranelli, C., Pastorelli, C., Bandura, A., \& Zimbardo, P. G. (2000). Prosocial foundations of children's academic achievement. Psychological Science, 11, 302-306. http://dx.doi.org/10.1111/14679280.00260 
Carlo, G. (2014). The development and correlates of prosocial behavior. In M. Killen \& J. Smetana (Eds.), Handbook of moral development (pp. 208-234). New York, NY: Psychology Press. http://dx.doi.org/10.4324/ 9780203581957.ch10

Carlo, G., McGinley, M., Hayes, R. C., \& Martinez, M. M. (2012). Empathy as a mediator of the relations between parent and peer attachment and prosocial and physically aggressive behaviors in Mexican American college students. Journal of Social and Personal Relationships, 29, 337-357. http://dx.doi.org/10.1177/0265407511431181

Carlo, G., Mestre, M. V., McGinley, M. M., Tur-Porcar, A., Samper, P., \& Opal, D. (2014). The protective role of prosocial behaviors on antisocial behaviors: The mediating effects of deviant peer affiliation. Journal of Adolescence, 37, 359-366. http://dx.doi.org/10.1016/j.adolescence.2014 .02 .009

Choukalis, C. G., Melby, J. N., \& Lorenz, F. O. (2000). Intraclass correlation coefficients in SPSS. Ames: Institute for Social and Behavioral Research, Iowa State University.

Costin, S. E., \& Jones, D. C. (1992). Friendship as a facilitator of emotional responsiveness and prosocial interventions among young children. $D e-$ velopmental Psychology, 28, 941-947. http://dx.doi.org/10.1037/00121649.28.5.941

Crick, N. R. (1996). The role of overt aggression, relational aggression, and prosocial behavior in the prediction of children's future social adjustment. Child Development, 67, 2317-2327. http://dx.doi.org/10.2307/ 1131625

Crockenberg, S., Jackson, S., \& Langrock, A. M. (1996). Autonomy and goal attainment: Parenting, gender, and children's social competence. In M. Killen (Ed.), Children's autonomy, social competence, and interactions with adults and other children: Exploring connections and consequences (pp. 41-55). San Francisco, CA: Jossey-Bass. http://dx.doi.org/ 10.1002/cd.23219967305

Davidov, M., \& Grusec, J. E. (2006). Untangling the links of parental responsiveness to distress and warmth to child outcomes. Child Development, 77, 44-58. http://dx.doi.org/10.1111/j.1467-8624.2006.00855.x

Day, R. D., \& Padilla-Walker, L. M. (2009). Mother and father connectedness and involvement during early adolescence. Journal of Family Psychology, 23, 900-904. http://dx.doi.org/10.1037/a0016438

Deković, M., \& Janssens, J. M. (1992). Parents' child-rearing style and child's sociometric status. Developmental Psychology, 28, 925-932. http://dx.doi.org/10.1037/0012-1649.28.5.925

Domitrovich, C. E., \& Bierman, K. L. (2001). Parenting practices and child social adjustment: Multiple pathways of influence. Merrill-Palmer Quarterly, 47, 235-263. http://dx.doi.org/10.1353/mpq.2001.0010

Dyer, W., Day, R. D., \& Harper, J. M. (2013). Wrestling proteus: Assessing the varying nature of father involvement across contexts. Journal of Marriage and Family, 75, 837-857. http://dx.doi.org/10.1111/jomf .12036

Dyer, W. J., Day, R. D., \& Harper, J. M. (2014). Father involvement: Identifying and predicting family members' shared and unique perceptions. Journal of Family Psychology, 28, 516-528. http://dx.doi.org/10 $.1037 / \mathrm{a} 0036903$

Eberly, M. B., \& Montemayor, R. (1998). Doing good deeds an examination of adolescent prosocial behavior in the context of parent-adolescent relationships. Journal of Adolescent Research, 13, 403-432. http://dx .doi.org/10.1177/0743554898134003

Eberly, M. B., \& Montemayor, R. (1999). Adolescent affection and helpfulness toward parents: A 2-year follow-up. The Journal of Early Adolescence, 19, 226-248. http://dx.doi.org/10.1177/0272431699019002005

Eisenberg, N. (1983). Children's differentiations among potential recipients of aid. Child Development, 54, 594-602. http://dx.doi.org/10.2307/ 1130046

Eisenberg, N., Guthrie, I. K., Cumberland, A., Murphy, B. C., Shepard, S. A., Zhou, Q., \& Carlo, G. (2002). Prosocial development in early adulthood: A longitudinal study. Journal of Personality and Social
Psychology, 82, 993-1006. http://dx.doi.org/10.1037/0022-3514.82.6 993

Eisenberg, N., Guthrie, I. K., Murphy, B. C., Shepard, S. A., Cumberland, A., \& Carlo, G. (1999). Consistency and development of prosocial dispositions: A longitudinal study. Child Development, 70, 1360-1372. http://dx.doi.org/10.1111/1467-8624.00100

Eisenberg, N., \& McNally, S. (1993). Socialization and mothers' and adolescents' empathy-related characteristics. Journal of Research on Adolescence, 3, 171-191. http://dx.doi.org/10.1207/s15327795jra0302_4

Eisenberg, N., Spinrad, T. L., \& Knafo-Noam, A. (2015). Prosocial development. In R. M. Lerner (Eds.), Handbook of child psychology and developmental science (7th ed., pp. 184-207). New York, NY: Wiley. http://dx.doi.org/10.1002/9781118963418.childpsy315

Elgar, F. J., Mills, R. S., McGrath, P. J., Waschbusch, D. A., \& Brownridge, D. A. (2007). Maternal and paternal depressive symptoms and child maladjustment: The mediating role of parental behavior. Journal of Abnormal Child Psychology, 35, 943-955. http://dx.doi.org/10.1007/ s10802-007-9145-0

Fagan, J., Day, R., Lamb, M. E., \& Cabrera, N. J. (2014). Should researchers conceptualize differently the dimensions of parenting for fathers and mothers? Journal of Family Theory \& Review, 6, 390-405.

Fortuna, K., \& Knafo, A. (2014). Parental and genetic contributions to prosocial behavior during childhood. In L. M. Padilla-Walker \& G. Carlo (Eds.), Prosocial development: A multidimensional approach (pp. 70-89). New York, NY: Oxford University Press. http://dx.doi.org/10 1093/acprof:oso/9780199964772.003.0004

Fujisawa, K. K., Kutsukake, N., \& Hasegawa, T. (2008). Reciprocity of prosocial behavior in Japanese preschool children. International Journal of Behavioral Development, 32, 89-97. http://dx.doi.org/10.1177/ 0165025407084055

Grusec, J. E., \& Davidov, M. (2010). Integrating different perspectives on socialization theory and research: A domain-specific approach. Child Development, 81, 687-709. http://dx.doi.org/10.1111/j.1467-8624.2010 .01426.x

Grusec, J. E., \& Goodnow, J. J. (1994). Impact of parental discipline methods on the child's internalization of values: A reconceptualization of current points of view. Developmental Psychology, 30, 4-19. http:// dx.doi.org/10.1037/0012-1649.30.1.4

Güroğlu, B., van den Bos, W., \& Crone, E. A. (2014). Sharing and giving across adolescence: An experimental study examining the development of prosocial behavior. Frontiers in Psychology, 5, 291.

Hall-Lande, J. A., Eisenberg, M. E., Christenson, S. L., \& NeumarkSztainer, D. (2007). Social isolation, psychological health, and protective factors in adolescence. Adolescence, 42, 265-286.

Hart, C. H., DeWolf, D., Wozniak, P., \& Burts, D. C. (1992). Maternal and paternal disciplinary styles: Relations with preschoolers' playground behavioral orientations and peer status. Child Development, 63, 879892. http://dx.doi.org/10.2307/1131240

Hart, C. H., Nelson, D. A., Robinson, C. C., Olsen, S. F., \& McNeillyChoque, M. K. (1998). Overt and relational aggression in Russian nursery-school-age children: Parenting style and marital linkages. Developmental Psychology, 34, 687-697. http://dx.doi.org/10.1037/00121649.34.4.687

Hastings, P. D., McShane, K. E., Parker, R., \& Ladha, F. (2007). Ready to make nice: Parental socialization of young sons' and daughters' prosocial behaviors with peers. The Journal of Genetic Psychology: Research and Theory on Human Development, 168, 177-200. http://dx.doi.org/10 .3200/GNTP.168.2.177-200

Hastings, P. D., Utendale, W. T., \& Sullivan, C. (2007). The socialization of prosocial development. In J. E. Grusec \& P. D. Hastings (Eds.), Handbook of socialization (pp. 638-664). New York, NY: Guilford Press.

Hastings, P. D., Zahn-Waxler, C., Robinson, J., Usher, B., \& Bridges, D. (2000). The development of concern for others in children with behavior 
problems. Developmental Psychology, 36, 531-546. http://dx.doi.org/10 .1037/0012-1649.36.5.531

Holmbeck, G. N., Li, S. T., Schurman, J. V., Friedman, D., \& Coakley, R. M. (2002). Collecting and managing multisource and multimethod data in studies of pediatric populations. Journal of Pediatric Psychology, 27, 5-18. http://dx.doi.org/10.1093/jpepsy/27.1.5

Kuczynski, L., \& Hildebrandt, N. (1997). Models of conformity and resistance in socialization theory. In J. E. Grusec \& L. Kuczynski (Eds.), Parenting and children's internalization of values (pp. 227-256). New York, NY: Wiley.

Laible, D., McGinley, M., Carlo, G., Augustine, M., \& Murphy, T. (2014). Does engaging in prosocial behavior make children see the world through rose-colored glasses? Developmental Psychology, 50, 872-880. http://dx.doi.org/10.1037/a0033905

Lewis, M. E. (2014). Parents as recipients of adolescent prosocial behavior. In L. M. Padilla-Walker \& G. Carlo (Eds.), Prosocial development: A multidimensional approach (pp. 305-326). New York, NY: Oxford University Press. http://dx.doi.org/10.1093/acprof:oso/9780199964772 .003 .0015

Little, T. D. (2013). Longitudinal structural equation modeling. New York, NY: Guilford Press.

MacDonald, K. (1992). Warmth as a developmental construct: An evolutionary analysis. Child Development, 63, 753-773. http://dx.doi.org/10 $.2307 / 1131231$

Melby, J., Conger, R., Book, R., Rueter, M., Lucy, L., Repinski, D., . . . Scaramella, L. (1998). The Iowa family interaction rating scales. In P. Kerig \& K. Lindahl (Eds.), Family observational coding systems: Resources for systematic research (5th ed., pp. 1-351). Mahwah, NJ: Erlbaum.

Moilanen, K. L., Rasmussen, K. E., \& Padilla-Walker, L. M. (2015). Bidirectional associations between self-regulation and parenting styles in early adolescence. Journal of Research on Adolescence. Advance online publication.

Muris, P., Meesters, C., Morren, M., \& Moorman, L. (2004). Anger and hostility in adolescents: Relationships with self-reported attachment style and perceived parental rearing styles. Journal of Psychosomatic Research, 57, 257-264. http://dx.doi.org/10.1016/S0022-3999(03)00616-0

Padilla-Walker, L. M. (2014). Parental socialization of prosocial behavior. In L. M. Padilla-Walker \& G. Carlo (Eds.), Prosocial development: A multidimensional approach (pp. 131-155). New York, NY: Oxford University Press. http://dx.doi.org/10.1093/acprof:oso/9780199964772 .003 .0007

Padilla-Walker, L. M., \& Carlo, G. (Eds.). (2014). Prosocial development: A multidimensional approach. New York, NY: Oxford University Press. http://dx.doi.org/10.1093/acprof:oso/9780199964772.001.0001

Padilla-Walker, L. M., Carlo, G., Christensen, K. J., \& Yorgason, J. B. (2012). Bidirectional relations between authoritative parenting and adolescents' prosocial behaviors. Journal of Research on Adolescence, 22, 400-408. http://dx.doi.org/10.1111/j.1532-7795.2012.00807.x
Padilla-Walker, L. M., \& Christensen, K. J. (2011). Empathy and selfregulation as mediators between parenting and adolescents' prosocial behavior toward strangers, friends, and family. Journal of Research on Adolescence, 21, 545-551. http://dx.doi.org/10.1111/j.1532-7795.2010 .00695.x

Padilla-Walker, L. M., Fraser, A. M., Black, B. B., \& Bean, R. A. (2015). Associations between friendship, sympathy, and prosocial behavior toward friends. Journal of Research on Adolescence, 25, 28-35. http://dx .doi.org/10.1111/jora.12108

Padilla-Walker, L. M., Harper, J. M., \& Bean, R. A., (2011). Pathways to parental knowledge: The role of family process and family structure. Journal of Early Adolescence, 31, 604-627.

Pardini, D. A., Fite, P. J., \& Burke, J. D. (2008). Bidirectional associations between parenting practices and conduct problems in boys from childhood to adolescence: The moderating effect of age and AfricanAmerican ethnicity. Journal of Abnormal Child Psychology, 36, 647662. http://dx.doi.org/10.1007/s10802-007-9162-z

Perez-Albeniz, A., \& de Paul, J. (2004). Gender differences in empathy in parents at high- and low-risk of child physical abuse. Child Abuse \& Neglect, 28, 289-300. http://dx.doi.org/10.1016/j.chiabu.2003.11.017

Peterson, C., \& Seligman, M. E. P. (2004). Character strengths and virtues: A handbook and classification. Washington, DC: Oxford University Press.

Pleck, J. H. (2007). Why could father involvement benefit children? Theoretical perspectives. Applied Developmental Science, 11, 196-202. http://dx.doi.org/10.1080/10888690701762068

Pleck, J. H. (2010). Paternal involvement: Revised conceptualization and theoretical linkages with child outcomes. In M. E. Lamb \& M. E. Lamb (Eds.), The role of the father in child development (5th ed., pp. 58-93) Hoboken, NJ: Wiley.

Roberts, W. L. (1999). The socialization of emotional expression: Relations with prosocial behaviour and competence in five samples. Canadian Journal of Behavioural Science/Revue canadienne des sciences du comportement, 31, 72-85. http://dx.doi.org/10.1037/h0087075

Robinson, C. C., Mandleco, B., Olsen, S. F., \& Hart, C. H. (2001). The parenting styles and dimensions questionnaire (PSQD). In B. F. Perlmutter, J. Touliatos, \& G. W. Holden (Eds.), Handbook of family measurement techniques: Vol. 3. Instruments \& index (pp. 319-321). Thousand Oaks, CA: Sage.

Steinberg, L., \& Silk, J. S. (2002). Parenting adolescents. In M. H. Bornstein (Ed.), Handbook of parenting: Vol. 1. Children and parenting (pp. 103-133). Mahwah, NJ: Erlbaum.

Stolz, H. E., Barber, B. K., \& Olsen, J. A. (2005). Toward disentangling fathering and mothers: An assessment of relative importance. Journal of Marriage and Family, 67, 1076-1092. http://dx.doi.org/10.1111/j.17413737.2005.00195.x

Received March 27, 2015

Revision received August 20, 2015

Accepted August 23, 2015 